\title{
Un Octaedro del Octaedro de Julio Cortázar
}

"Rayuela/es de alguna manera la filosofía de mis cuentos, una indagación sobre lo que determinó a lo largo de muchos años su materia o su impulso" - confiesa Julio Cortázar en La vuelta al día en ochenta mundos, ${ }^{1}$ lo que ha sido verdad hasta la aparición de su nuevo volumen de cuentos publicado con el título de Octaedro. ${ }^{2}$ No es que Rayuela haya dejado de funcionar como explicación "con reflexiones", de servir de materia prima con su enorme riqueza de temas y medios, pues a renglón seguido veremos en cuántas partes se anticipa Cortázar a varias ideas y situaciones expuestas en Octaedro. En realidad, ha escrito un cuento titulado "Manuscrito hallado en un bolsillo", ${ }^{3}$ el cual no necesita ya la susodicha filosofía, dado que el cuento alcanza a ser nada menos que la continuación de Rayuela, esa novela que Fuentes llama "la caja de Pandora". El cuento-que evidentemente es el mejor del volumen-retoma el hilo que empezó en "El perseguidor", donde el autor argentino por primera vez dejó de lado las invenciones fantásticas y abordó "un problema existencial, de tipo humano", como el propio Cortázar lo ha afirmado en una entrevista. ${ }^{4}$ Dicho tema se amplió en Los premios y culminó en Rayuela. Ahora con la creación de "Manuscrito" disponemos de una obra cortazariana que no sólo sigue el camino "existencial, humano", sino que, también, en muchos aspectos, conlleva una similitud con Rayuela, y de cierto modo, es la misma Rayuela.

Es sabido que Cortázar siempre hace hincapié en la semejanza de sus cuentos y novelas ${ }^{5}$ poniendo de relieve a la vez que en lo que difieren sus obras son únicamente en las perspectivas escogidas por el autor, lo que nos parecía

1 Ed. Siglo XXI (México, 1967), p. 25.

2 Cortázar, J., Octaedro (Madrid: Alianza Editorial, 1974).

3 Ibid., pp. 49.65. En lugar del título completo desde ahora utilizaremos la primera palabra: Manuscrito.

4 Harss, L., Los nuestros (Buenos Aires: Editorial Sudamericana, 1966).

5 Véase, por ejemplo, La vuelta..., pp. 25-26. 
siempre aceptable, pero nunca hemos visto una realización tan directa de este principio como en el caso de "Manuscrito" y Rayuela. En una conferencia sobre el cuento, ${ }^{6}$ Julio Cortázar sefaló que la diferencia entre novela y cuento se la puede caracterizar con un partido de boxeo: ganado por puntos (novela) o por knockout (cuento). Pues bien, en este estudio trataremos de descifrar las principales claves de interpretación de la indiscutible victoria del cuento "Manuscrito hallado en un bolsillo".

\section{ESTRUCTURACION BINARIA}

La duplicidad como caracteristica general de la obra cortazariana evidentemente surgió antes de que apareciera Rayuela. Ya en "Lejana"7 vimos un mundo doble (Buenos Aires y Budapest) a través de los ojos de la protagonista, pero fue en esa novela donde la división binaria tanto del mundo objetivo como del subjetivo llegó a ser dominante en todos los níveles de la obra. En cuanto al espacio representado de tal manera, basta acordarnos de las ciudades de Paris y Bụenos Aires, las cuales dialécticamente se complementan en toda la novela, deslizándose una a la otra porque no pueden representar el mundo sino juntas. El dibujo de la rayuela misma, este mundo reducido, tiene también dos polos: el Cielo y la Tierra. Ahora bien, en "Manuscrito" la misma estructura se repite esta vez verticalmente: París está dividido en un mundo de arriba y en el subterráneo que es el metro, la vasta "superficie de subtendidos seudópodos". La camunicación entre las dos esferas no es tan fácil como nos puede parecer en el mundo cotidiano, pues se trata de una ruptura total ("ruptura" es justamente la primera palabra enfática del cuento) donde el descenso implica una metamorfosis del pasajero. Esta idea no es nada nueva en la narrativa cortazariana, pues en 62 . Modelo para armar, que pertenece orgánicamente a Rayuela, se lee un pasaje que dice: "Cada vez que Hélène bajaba a la estación Malesherbes, se empecinaba en mirar la calle hasta el último momento, a riesgo de tropezar y perder equilibrio, prolongando un placer indefinido que también tenla algo de repugnante en esa sumersión paulatina peldaño a peldaño, asistiendo a la metamorfosis voluntaria en que la luz y el espacio de lo diurno se iban anulando hasta entregarla, Ifigenia cotídiana, a un reino de irrisorias lamparillas, a una húmeda circulación de bolsillos y periódicos leídos." " La vía al revés tampoco es menos difícil, el protagonista (actor-autor) falla justamente en este punto del juego cuando los logros alcanzados debajo de la tierra no los puede continuar en el mundo de arriba, y debe pararse en las salidas de las estaciones del metro. Cabe recordar aquí que el cuento, el manuscrito, se escribe justamente en una estación del metto, es decir en la ruptura mistra, en un "húeco" como diría Cortázar, en un "agujero" como diría Johntiy de "El perseguidor", pues todos son intermediarios, tierras de nadie de donde uno puede encaminarse en ambas direcciones: hacia el cielo o hacix ih tierra.

\footnotetext{
6 "Algunos aspectos del cuento", (Casa de las Américas, La Habana, núms. 15-16), pp. 3-14.

7 Cortázar, J., Bestiario (Buenos A ires: Editorial Sudamericana, 1971), pp. 35-51.

8 Cortázar, J., 62. Modelo para armar (Buenos Aires: Editotial Sudamericana, 1968), pp. 101.
} 
Analizando los planos temporales nos damos cuenta de la misma estructuración binaria, ya que el presente del cuento no es sino un pasado condicional o un futuro condicional. El protagonista que empieza el juego ahora en el metro es un personaje que lleva en su memoria todos los recuerdos de las tentativas frustradas en el juego, pero al tomar el metro, al descubrir el reflejo de la muchacha en la ventanilla, es entonces el futuro lo que le va iluminando. Lo mismo se refiere a la chica parisiense en cuyo caso Cortázar se vale de varios nombres para hacer las distinciones mencionadas: Ana-la muchacha que está sentada frente al protagonista - es ora Paula (pasado) cuando rechaza participar en el juego, ora Margrit (futuro) si contesta con una sonrisa y entonces será Marie-Claude en el mundo de arriba. El presente del protagonista es un interregno, un estado eventual donde el fracaso del pasado y la esperanza en un futuro encuentro se unen en el momento del juego.

Pero no solamente el mundo está dividido en dos: los individuos que lo habitan también tienen la misma estructura. El elemento del doble, del doppelgänger, es un factor constante en la narrativa cortazariana: ya en "Casa tomada" surge el primer ejemplo, caso arquetípico; lo sigue el doble en "Las puertas del cielo", los de "Lejana", "La noche boca arriba", "Las armas secretas", "La isla a mediodía", etc. En Rayuela se ve ya una elaboráción tan compleja del tema que los mismos personajes (Oliveira y Traveler) se ponen a discutir quién de los dos es el verdadero doble. 9 En el caso de "Manuscrito" tampoco es menos complicado el cuadro si tomamos en cuenta todos los dobles de los protagonistas, pues cabe distinguir tres niveles y en cada uno de ellos aparecen los dobles. Para facilitar la distinción de los personajes, Cortázar les pone nombres diferentes para cada fase. La muchacha parisiense se llama Ana cuando está sentada en un banco frente al protagonista a quien llamaremos Julio. Sin embargo, en el momento cuando aparece el reflejo de la chica en la ventanilla del vagón del metro, ella tiene el nombre de Margrit, pues ya es otra persona, es el doble de Ana. Lo mismo sucede con Julio, cuyo reflejo también se ve en el vidrio, y al cruzar las dos miradas, "mi reflejo en el vidrio no era el hombre sentado frente a Ana...y además, la que estaba mirando mi reflejo ya no era Ana sino Margrit...". ${ }^{10}$ Es que en el metro, en el mundo de abajo, hay cuatro personas que toman parte en el juego.

Una vez logrado el juego, cumplidas las reglas predeterminadas, los dos protagonistas con sus dobles suben al mundo de arriba y se convierten en MarieClaude y otro Julio respectivamente. Este Julio ( $\mathrm{Julio}_{3}$ ) ha dejado de ser el de abajo, mejor dicho los de abajo (Julio ${ }_{1}$ y $\mathrm{Julio}_{2}$ ), es ya un nuevo Julio quien va a encontrarse con el doppelgänger (Marie-Claude) de la chica (Ana) cuyo reflejo (Margrit) se cruzó con el suyo en el vagón del metro. Si añadimos a todos éstos

9 Rayuela (La Habana: Editorial Casa de las Américas, 1969), pp. 406 y 412, citada en las notas 24 y 25 .

10 Manuscrito, p. 53. 
las variantes temporales: a Paula (Ofelia) quienes no se separan ya en el cuento, dado que simbolizan a todas las Anas y Margrits anteriores, es decir los fracasos del pasado, y si se agrega a los Julios anteriores (Julio $n$ ) también, obtendremos un octaedro ${ }^{11}$ como resultado de las distintas combinaciones del doble que se dan en el tiempo y en el espacio:

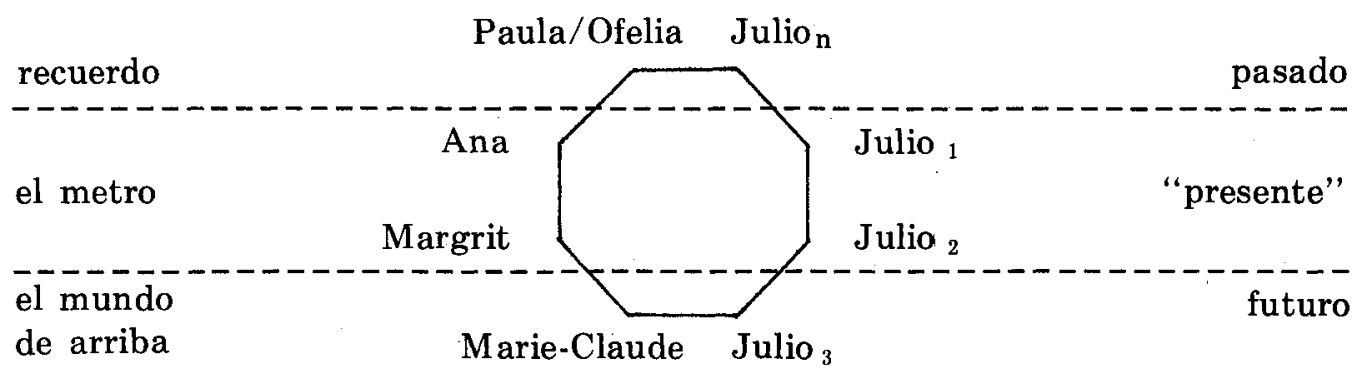

Al examinar esta ilustración uno se pregunta si nuestro octaedro no representa en realidad la teoría de Unamuno expuesta en el "Prólogo a las tres novelas ejamplares", ${ }^{2}$ donde propone que cuando dos personas (Juan y Tomás) hablan, en realidad son ocho los que participan en la conversación: el Juan real, el Juan ideal (el que cree ser), el Juan que quisiera ser y. el Juan ideal de Tomás; los otro cuatro se forman de los Tomases de manera idéntica. Aparentemente los Julios $\mathrm{n}$ del pasado coinciden con el Juan real, Julio ${ }_{2}$ con el Juan ideal de Tomás, y Julio ${ }_{3}$ con el Juan que quisiera ser. Pero hay una diferencia básica entre el sistema cortazariano y el de Unamuno: el autor español habla de las diferentes caras de una única persona, quien se ve distinta según la luz que la alumbre; y más aún, en la teoría de Unamuno los tres Juanes quedan subordinados al Juan que quisiera ser, ya que en realidad es la voluntad que distingue al Juan real de los demás. En el caso de Cortázar el doble siempre implica la ampliación del yo: un personaje puede ser un niño y un viejo simultáneamente ("La flor amarilla"), puede ser amante y esposa agonizante a la vez ("El río"), etc., pues se trata de un "verdadero enriquecimiento vital" , 13 y además, una figura cortazariana o su doble puede unirse, identificarse con otra figura o con su doppelgänger (por ejemplo en "Lejana", "Axolotl", etc.). Será justamente esta última función de los personajes del autor argentino (quienes de verdad son dos o más personas), por la cual Cortázar trata de resolver "el problema existencial" como lo veremos más adelante.

\section{EL METRO-MANDALA}

"A veces me convenzo de que la estupidez se llama triángulo, de que ocho

11 Para simplificar la ilustración hemos dibujado un octógono.

12 Véase en La generación del 98 (La Habana: Editorial Instituto del Libro, 1970), pp. 249-250.

13 Morello-Frosch, M., "El personaje y su doble en las ficciones de Cortázar", en Revista Iberoamericana (Pittsburgh, vol. XXXIV, No. 66, jul.-dic., 1968), p. 324. 
por ocho es la locura o un perro", se dice en Rayuela,${ }^{14}$ contra lo absurdo de los ejes, centros, geometrías, "nombres de la nostalgia indoeuropea". Así tenemos una razón más para señalar que el doble plano—sin duda alguna-no puede ser un fin estético para Cortázar, sino que es un mero elemento estructural, es also artificialmente abstraído; lo consideramos como una instantánea radiográfica que captó nada más que un segundo de la realidad en movimiento, en cambio permanente. "No hay centro-dice Oliveira,-hay una especie de confluencia continua, de ondulación de la materia." 15

Uno de los medios preferidos de Cortázar pará poner en movimiento el sistema de los dobles es el juego. En su narrativa no se trata de elementos lúdicos, de irrealidades aceptadas en lugar de realidades; Cortázar introduce sus juegos como fenómenos existenciales. De allí que prefiere los juegos libres, de variantes múltiples, donde los personajes y sus dobles fácilmente pueden vivir sus vidas independendientes. Le encantan los juegos infantiles y la pasión con la cual participan los niños en ellos. Es sabido que Rayuela originalmente iba a llamarse "Mandala", ese laberinto místico de los budistas que con un círculo dividido en casillas abarca todo el universo. Las posibilidades de la rayuela las conocemos todos, así como las variantes, las posibles lecturas de Rayuela también han sido analizadas debidamente en varios ensayos durante los últimos diez años. En el cuento que estamos analizando Cortázar desarrolla otro juego de tipo mandala para lo cual le sirve el metro, tema recurrente de toda su narrativa.

En "El perseguidor" ya se anticipa la importancia que Cortázar atribuye al metro: Johnny (Charlie Parker) varias veces trata de explicar a Bruno su obsesión del tiempo relativo de los cronopios valiéndose del ejemplo del metro, donde las estaciones significan los minutos bien determinados durante los cuales él recuerda horas y horas del pasado. Después de este tratamiento temporal del tema, en Rayuela surge el metro como símbolo espacial. Primero llegamos a saber que " - En el fondo-dice Gregorovius - , París es una enorme metáfora'/416 después ya se anuncia el tema de "Manuscrito": "París es un centro, una mandala que hay que recorrer sin dialécticas". ${ }^{17}$ Toda esa anticipación culmina en las escenas de 62. Modelo para armar, donde Hélène ya es casi el futuro protagonista, Julio, cuando piensa "...ahora ese París subterráneo que durante algunos minutos la llevaría también a través de un sistema ineludible de pasajes y vías, la aliviaba extrañamente de su libertad, le permitía quedarse como en ella misma, distraída y a la vez concentrada..."18 Pues, el tema, las ideas ya estaban "en el aire" desde hace varios años, casi se esperaba ya en cuento que lo elaborara.

14 Rayuela, p. 23.

15 Ibid., p. 290.

16 Ibid., p. 160.

17 Ibid., p. 500.

18 62. Modelo para armar, p. 102. 
El metro, por naturaleza, cumple los criterios necesarios para los sistemas de tipo mandala: es un laberinto que nos rodea; cubre todo el ámbito de la ciudad con su vasta red de líneas, es decir, es muy apto para simbolizar el todo, pues reduce la totalidad del espacio, el mundo entero en su sistema subterráneo. De manera igual a las mandalas y las rayuelas, el metro también está dividido en casillas: en estacionès, las cuales son puntos fijos, independientes de la gente que viaje por ahí, lo que es de gran trascendencia para Cortázar, pues lo externo debe ser invariable para servir de reglas de juego. El número de las líneas, estaciones, salidas, escaleras es finito, pero ellas rinden posibilidades infinitas con sus combinaciones y salidas que se abren en cada estación del metro. Además, cada estación puede servir de centro (como lo determinará el juego) de todo el sistema; así el metro parece ser muy adecuado para simbolizar la búsqueda de los protagonistas por un centro, que en realidad no es el centro geométrico de la mandala, sino un punto desde donde todo el sistema tendrá sentido. $Y$, por fin, las variedades infinitas de posibles viajes en el metro facilitan la representación dramática del azar, elemento indispensable para los juegos.

Después de haber visto los dos grandès pilares de "Manuscrito", entre los marcos de los cuales se desarrolla todo el cuento, el juego, veamos el sistema en funcionamiento y algunos de los logros alcanzados.

\section{ALCANCES}

1. Circularidad. El primer resultado que salta a la vista al leer "Manuscrito" es un dinamismo, un ritmo que se apodera del lector y lo lleva sin parar. Este movimiento que fluye en las palabras en realidad no es sino aquella ondulación "confluencia de la materia" que hemos mencionado más arriba, la cual se crea justamente por la combinación de dos elementos estructurales; el doble y el juego. El juego comienza con el hecho de que un pasajero baja al metro con el fin de reanudar un juego inventado por él; después nos damos cuenta que una muchacha está sentada frente a él junto a la ventanilla; dentro de poco aparecen los dobles de ambos personajes en el vidrio. Es decir, hablando una vez más en términos geométricos, desde un punto llegamos a un cuadrado. Este cuadrado en cada momento tiene dos posibilidades latentes: ora se deshace (y Ana/Margrit se convertirán en Paula/Ofelia, los dos Julios a su vez en Julios del pasado), ora sigue desenvolviéndose, tomando rumbo hacia el futuro: Ana/Margrit serán MarieClaude y los dos Julios crean a un Julio nuevo $\left(\mathrm{Julio}_{3}\right.$ ). Una vez llegado el proceso a este punto, ya estamos en el mundo de atriba, los dos personajes pueden encontrarse y-como vemos en el cuento-unirse en el acto de amor. Pues el cuento arranca de un punto ( $\mathrm{Julio}_{1}$ ) y termina en otro (Marie-Claude más $\mathrm{Julio}_{3}$ ), y esa enorme diferencia que existe entre los dos extremos justifica todo el juego, todo el cuento. Pero Cortázar no queda satisfecho con este círculo completo, esta mandala que rodea a todos los participantes: nos hace creer que la uniớn con Marie-Claude se realizó sólo a través del acto de violar las reglas del juego, pues no hay otra solución: Marie-Claude y Julio se añaden a las Paulas/Ofelias y a los Julios fracasados respectivamente, y si quieren alcanzar un 
encuentro regular, deben otra vez bajar al metro, desdoblarse en sus doppelgängers y empezar otra vez el juego. Con una vuelta completa y otra iniciada Cortázar describe un movimiento circular en funcionamiento: no hay ni un segundo de estabilidad, el proceso corre y corre del presente al futuro, del futuro al pasado, del pasado al presente.

2. Lector-cómplice. En Ultimo round Julio Cortázar confiesa que sus cuentos siempre han tenido por fin de que el lector tenga "la sensación de que en cierto modo está leyendo algo que ha nacido por sí mismo, en sí mismo y hasta de sí mismo". ${ }^{9}$ Es por eso en realidad que casi siempre utiliza la primera persona como forma de narración, porque en este caso narración y acción son la misma cosa ${ }^{20}$ Toda la estructuración de "Manuscrito" refleja este propósito del autor, pues el cuento comienza in media res, con el juego en desenvolvimiento, y a la vez el lector va estudiando las reglas del juego. Al terminar la primera vuelta, el lector ya es cómplice del autor: lamenta mucho que la unión de Marie-Claude y Julio ${ }_{3}$ (es decir, el éxito del juego) haya resultado ser una victoria falsa. Y ocurre entonces que Cortázar agarra al lector y lo pone en el punto de partida para que ahora juegue él por sí solo, y el escritor-quien "supo abrir la puerta para ir a jugar" 21 -se retira. Cabe recordar que este instante en el cuento no es todavía el knockout de que habló Cortázar; el verdadero fin del cuento alcanza al lector jugando, y el knockout no es el fracaso de Marie-Claude y Julio del cual el lector ha sido testigo, sino el momento cuando el lector se ve obligado a darse cuenta que él mismo está jugando y la vuelta iniciada debe ser terminada por él. El autor original a su vez se convierte en observador: está ahí en la estación de Chemin Vert, sentado en un banco y escribiendo "el manuscrito", pues como nos ha advertido-entre otros lugares-en 62 . Modelo para armar: "Escribo por falencia, por descolocación, y como escribo desde un intersticio, estoy siempre invitando a que otros busquen los suyos y miren por ellos el jardín đonde los árboles tienen frutos que son, por supuesto, piedras preciosas." 22

3. "Auto-enfrentamiento". Los dobles son personas autónomas en la narrativa cottażariana; ${ }^{23}$ son tan independientes que muchas veces ni siquiera se sabe cuál de los dós es el doble: "sos mi doppelgänger porque todo el tiempo estoy yendo viniendo de tu territorio al mío, si es que llego al mío, y en estos pasajes lastimosos me parete que vos sos mi forma que se queda así mirándome con lástima..." ${ }^{24}$ - dice Oliveira a Traveler cuando por fin se encuentran, y éste a su vèz se defiende: "El verdadero doppelgänger sos vos, porque estás como

19 Ed. Siglo XXI, México, 1969, p. 36. Ver también Rayuela, pp. 512-513.

20 Ultimo round, p. 37.

21 Es el Gltimo verso de una.canción infantil argentina, citado en varias obras de Cortázar. Ver también el articulo de Rubén Benitez con el mismo título en Revista Iberoamericana (Pittsburgh, vol. XXXIX, 84-85, jul.-dic., 1973), pp. 483.503 .

22. 62. Modelo para armar, p. 71.

23 Véase el ensayo mencíonado en la nota 13.

24 Rayuela, p. 412. 
descarnado, sos una voluntad en forma de veleta, ahí arriba." ${ }^{25}$ En el cuento de "Manuscritó" es el mundo del metro y el juego lo que fuerza a los personajes a que sean del todo su propio doppelgänger; el reflejo (Margrit Julio ${ }_{2}$ ) no aparece en el mundo de arriba, es la oscuridad del túnel lo que "pone su azogue atenuado, su felpa morada y moviente que da a las caras una vida en otros planos, les quita esa horrible máscara de tiza de las luces municipales del vagón". 26 Lo mismo sucedió con Hélène en 62. Modelo para armar, donde el metro "le permitía quedarse como en ella misma". ${ }^{27}$ Es evidente que el doble, en el caso de Julio, es el reflejo del Julio que baja al metro para jugar, pero todos quisiéramos que sea el doppelgänger que suba al mundo de arriba pues para eso sirve el juego. Lo qup esperamos es un intercambio semejante al de Alina Reyes y la mendiga de Budapest como ocurre en "Lejana", en "Bestiario", ya que, en caso contrario, las arañas siguen mordiéndole al protagonista en el pozo del mundo de arriba. Pues por medio del metro y el juego Cortázar obliga a los personajes que se, encaren consigo mismos, que busquen al doble que sea capaz de superar los obstáculos inmensos en encontrar al otro, porque no hay otro remedio para aguantar la realidad que sustituirla con una llamada irrealidad que es la futura realidad.

4. El otro humano. Al juego le atribuye Cortázar muchas funciones, pero la más importante es la de ir más allá de lo cotidiano, descubrir "todo lo que está al otro lado de la Gran Costumbre", ${ }^{28}$ abrir una puerta hacia lo desconocido. Ejse otro lado puede significar una gran cantidad de cosas, de trascendencias, logros existenciales, amor, etc. El valor excepcional de "Manuscrito" se encuentra en el hecho de que Cortázar-continuando la línea de "El perseguidor" - Rayuela-una vez más habla del otro hombre. El fin deseado es un encuentro con alguien, y este alguien en "Manuscrito" es una figura real; ya no se trata del otro desdoblado (Lejana), tampoco del otro impersonal o innominado (Casa tomada), ni de los otros como grupo ajeno (Omnibus), Marie-Claude es una chica de carne y hueso, y el éxito del juego significa el encuentro de dos seres humanos, dos hombres que están en busca uno del otro. ¡Qué largo camino ha recorrido Cortázar desde Bestiario (desde las hormigas, cucarachas, conejitos) hasta llegar a hablar de dos hombres que se persiguen para escapar del mundo alienado!

Claro, no lo hace en forma directa; el medio es otra vez el juego (como en Rayuela) que se desarrolla en el metro, pues insiste en que "detesto las búsquedas solemnes". ${ }^{29}$ Ya hemos dicho que la duplicación del mundo y de llos personajes sirve para el enriquecimiento vital del protagonista: si sale del mundo de arriba, baja al metro y juega el juego inventado por él mismo, encontrará a su

25 Ibid., p. 406.

26 Manuscrito, p. 53.

27 Ver nota 18.

28 Ultimo round, p. 66.

29 Los nuestros, p. 281. 
doble, y el doble a su vez se hallará con el doble de alguien, y después los dos dobles y los originales regresan al mundo de donde escaparon; pero son completamente nuevos, ampliados: han encontrado al otro. O como Cortázar lo dijo en La vuelta al día en ochenta mundos: "Porque un juego, bien mirado, ¿no es un proceso que parte de una descolocación para llegar a una colocación, a un emplazamiento-gol, jaque mate, piedra libre? ¿No es el cumplimiento de una ceremonia que marcha hacia la fijación final que la corona?". ${ }^{30}$

Cabe señalar que esta "colocación", resultado máximo del juego, nace y se desarrolla a través de la mirada. Mirar, ver, han sido también palabras claves en las obras anteriores; pensemos, por ejemplo, en la escena de Rayuela, donde Oliveira daba lecciones a la Maga "sobre la manera de mirar y ver", 31 o en "Axolotl", donde el protagonista se identifica con el bicho raro mirándolo, o en el fotógrafo de "Las babas del diablo", etc. En "Manuscrito" la mirada parece ser el alma de todo el juego: no hay juego si la chica no mira al reflejo en el vidrio, ${ }^{32}$ las dos miradas deben cruzarse, los que no juegan, miran un periódico o "tienen los ojos perdidos en el hastío de ese interregno en el que todo el mundo parece consultar una zona de visión que no es la circundante", ${ }^{33}$ y se espera que "la mirada de Margrit cayera como un pájaro en su mirada", 34 etc. El propio Cortázar admite que "no hay necesidad de hablarse, nada se podría decir sobre ese muro impasible y desconfiado de caras y paraguas", 35 que separa a Julio del otro, de Marie-Claude: el puente al otro lado se construye por los ojos.

El éxito del juego no implica la realización del encuentro verdadero, sólo abre el camino, sólo asegura la posibilidad de que se produzca de veras una relación entre los dos. La primera oración (y la más encantadora del cuento) que dice Julio ${ }_{3}$ en el mundo de arriba, después de ganar el juego (aunque sea por haber transgredido las reglas) es: "No puede ser que nos separemos así, antes de habernos encontrado." 36 Pues el verdadero encuentro humano está por realizarse.

5. El azar. Uno de los mayores logros de la nueva novela hispanoamericana parece ser la introducción de temas, marcos y personajes ambiguos. No cabe duda alguna que Cortázar ha desempeñado un papel trascendental en el desarrollo de dichas ambigüedades, de visiones duales y plurales de la vida; su Rayuela no sólo fue la primera obra de esta tendencia, sino que la novela entera, en todos los niveles, representa una pluralidad nunca vista hasta 1963, la cual,

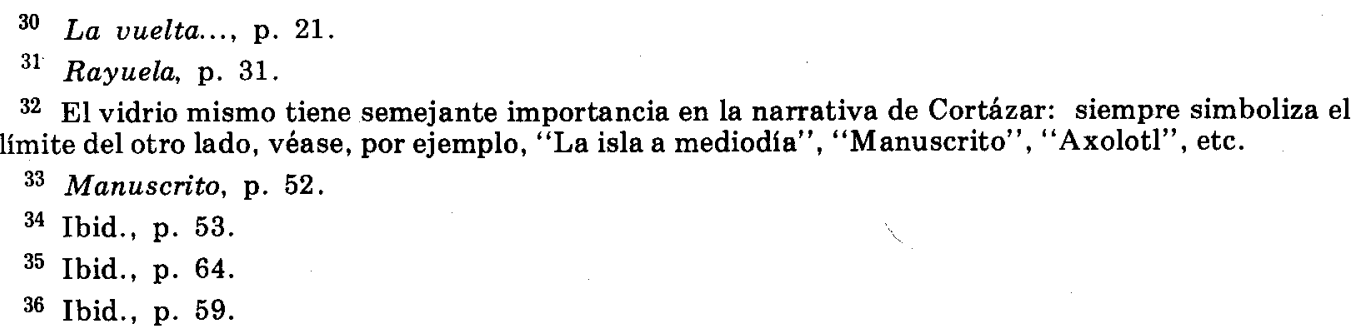


más tarde, será llevada hasta las últimas consecuencias en 62. Modelo para armar. En el cuento "Manuscrito" la estructuración dual, combinada con el juego, es un medio más que adecuado para crear ambigtiedades: hemos visto que en lugar de dos personajes debemos hablar de ocho, pues cada uno tiene dobles tanto en el tiempo como en el espacio. En cuanto al juego del metro, Cortázar siempre ha preferido los juegos libres a los de normas fijas, ${ }^{37}$ pues en aquéllos habrá más variedad, y, por consiguiente, el azạ tendrá más influencia. El metro proporciona un inmenso número de combinaciones y "cada estación del metro era una trama diferente del futuro porque así lo había decidido el juego". ${ }^{38}$ Pero es justamente eso lo que quiere Julio: tentar el azar, echar de lado toda la seudoseguridad del mundo de arriba, pues prefiere "los peores desencuentros a las cadenas estúpidas de una causalidad cotidiana". "39 Bueno ¿qué será este combate a ciegas: desesperación o suicido o locura? ¿Cómo encontrar alguien en el metro de París con tales reglas complejas de juego? El azar, según Cortázar, no es azar en el mundo de abajo, pues el metro está en otro plano que "responde a otras leyes, a otras estructuras", ${ }^{40}$ ahí aparecen las "figuras" cortazarianas, las euales "serían en cierto modo la culminación del tema del doble, en la medida en que se demostraría o se trataría de demostrar una concatenación una relación entre diferentes elementos que, vista desde un criterio lógico, es inconcebible". ${ }^{41}$ Esta noción de "figura" - aunque se realice en un plano no cotidiano, por no decir fantástico -, este azar estructurado, rompe las barreras del individuo, del mundo aislado, alienado, y abre ventanas que dan hacia las "constelaciones de personajes"; así una vez más llegamos a afirmar ese interés, cada vez más intensivo de Cortázar desde "El perseguidor" hasta "Manuscrito", por el otro ser humano. Y desde el punto de "vista de este triunfo-pues lo es de verascasi es insignificante que los personajes sean conscientes de ser partes de ciertas figuras, constelaciones o no, pues lo que les toca a ellos es tentar el azar y después las figuras se realizarán según sus propias leyes.

\section{EL DESENLACE}

A base de toda la narrativa cortazariana uno puede llegar a la conclusión de que los dobles son de veras ampliaciones del yo; pero, en fin de cuentas, los doppelgängers siempre quedan derrotados, $y$ los personajes siguen "descolocados" o se anonadan. Esta tendencia está ya bien estudiada, ${ }^{42}$ y bástenos aquí unos pocos ejemplos para recordar dichos fracasos de los protagonistas de Cortázar: "Lejana", "Axolotl", "El otro cielo", "El per-

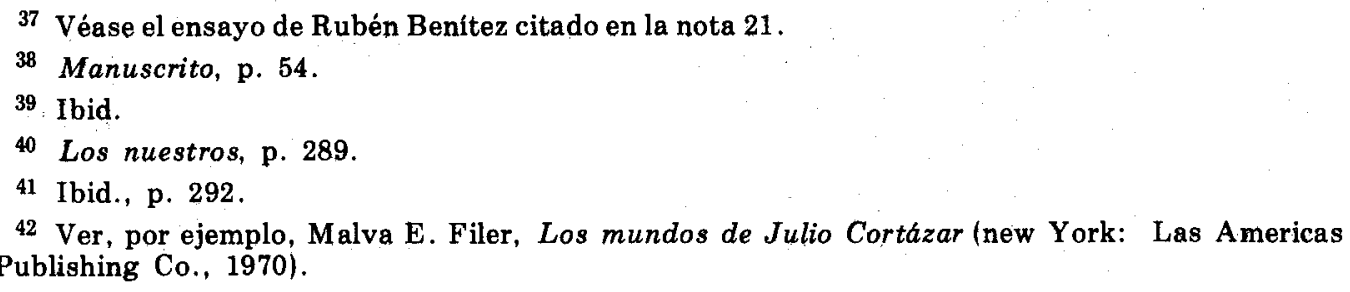


seguidor", etc. Pero a nuestro parecer hay dos excepciones: Rayuela y "Manuscrito". En la primera, la lectura principal termina con un encuentro frustrado, pero con la ventana abierta, pues nunca se sabe si se realiza el suicido o no; en la segunda, la desesperación del protagonista es evidente y todos nos damos cuenta de lo imposible que es el éxito del juego reanudado, pero el fracaso no se anuncia, el cuento termina antes de que ocurra la segunda derrota, así otra vez la obra queda abierta. De todo esto vemos que Cortázar ya no admite la derrota, pero tampoco consigue el triunfo perseguido; lo que le importa es la búsqueda misma. Esta persecución no tiene rumbo fijo - "me muevo como una hoja seca" ",43 - dice Oliveira en París. Así a veces puede tener la apariencia de ser un movimiento por el movimiento, como si fuera simplemente una forma de escape; pero ya en "El perseguidor" supimos que Johnny "no está escapando de nada. Ir a un encuentro no puede ser nunca escapar, aunque releguemos cada vez el lugar de la cita"; ${ }^{44}$ en Rayuela nos dimos cuenta que Horacio es un loco, pues "Adivina que en alguna parte de París, en algún día o alguna muerte o algún encuentro hay una llave...en realidad no tiene conciencia de que busca la llave, ni de que la llave existe"; ${ }^{45}$ y por fin en "Manuscrito" hemos visto que la búsqueda debe recorrer un laberinto, el metro-mandala, pero la motivación para tal viaje siempre es el encuentro con el otro (y en fin de cuentas con el verdadero yo), y aunque el primer encuentro no se declara válido, Marie-Claude y Julio ${ }_{3}$ inician una segunda vuelta, pues "No quisimos pensar en la improbabilidad..." 46 y pasan dos semanas en el mundo subterráneo buscándose.

Es decir, en este cuento de Octaedro Cortázar reafirma y concretiza de manera muy directa la importancia de la actitud ante la búsqueda; su personaje es totalmente consciente de las dificultades, las circunstancias desfavorables, sufre fracasos reiteradamente, sin embargo, no deja de jugar, sigue con la búsqueda a toda costa, y por la persecución al otro invita al lector a participar en el juego. Cortázar no garantiza éxitos; lo que exige es que todos traten de liberarse del sentimiento de descolocación ("de no estar del todo en cualquiera de las estructuras, de las telas que arma la vida y en las que somos a la vez araña y mosca" ${ }^{47}$ ), y que a través del juego se esfuercen por alcanzar el encuentro anhelado.

\section{LO NUEVO}

La importancia del cuento "Manuscrito hallado en un bolsillo" se halla en la continuación del tema humano comenzado con "El perseguidor". Cortázar ha dado un paso adelante en la concretización del conflicto existencial de nuestro siglo mostrándonos en forma inequívoca que lo otro es el otro ser humano que en

44 En Quince relatos de América Latina (La Habana: Casa de las Américas, 1970), p. 191.

Rayuela, p. 161.

46 Manuscrito, p. 62.

47 La vuelta..., p. 21. 
el presente cuento-después de tantas variantes desde animales hasta hombres impersonales-se personifica por Marie-Claude.

Al mismo tiempo hemos visto que el tema del metro no es nuevo, el doble, el juego son elementos bien conocidos de la narrativa anterior de Cortázar, los logros resumidos bajo las nociones de la circularidad, el lector-cómplice, el autoenfrentamiento y el azar tampoco conllevan novedades trascendentales en la obra cortazariana, como queda demostrado más arriba. Lo nuevo de este cuento se realiza en el tratamiento ${ }^{48}$ de todos estos factores, la combinación de los medios arriba expuestos de tal manera que en quince páginas - con máxima economía de sus recursos, ${ }^{49}$ con una tensión continua de fogosidad y con una espontaneidad increíble-Julio Cortázar logra repetir la complejidad maravillosa de Rayuela. Con este cuento el autor ha demostrado su dominio absoluto de los géneros narrativos. Triunfa con un knockout literario.

Universidad Eötvös Lorand, Budapest

LASZLO SCHOLZ

48 Véase el artículo del propio Cortázar, citado en nota 6.

49 Ver Ultimo round, p. 35. 